\title{
Developing a photonics education program at college level from the ground up
}

\section{Anca Sala}

Anca L. Sala, "Developing a photonics education program at college level from the ground up," Proc. SPIE 9188, Optics Education and Outreach III, 918803 (15 September 2014); doi: 10.1117/12.2061426

SPIE Event: SPIE Optical Engineering + Applications, 2014, San Diego, California, United States 


\title{
Developing a Photonics Education Program at College Level from the Ground Up \\ Anca L. Sala* \\ Baker College, 1050 W. Bristol Rd., Flint MI, USA 48507
}

\begin{abstract}
While graduate level optics and photonics education in the state of Michigan has a rich tradition, college level programs that produce photonics technicians are virtually non-existent. Baker College has started the first two-year photonics program in the state in fall 2013. The program is leveraging support from Mi-Light, the Michigan Photonics Cluster; OP-TEC, the National Center for Optics and Photonics Education; and an NSF Project Grant awarded to the College. In its first year the photonics program has achieved important milestones - convening an Advisory Board with industry participation, developing almost the entire curriculum, and creating a fully functional optics and photonics laboratory. Outreach activities have also taken place. The paper will describe the steps taken to introduce the new program and the lessons learned along the way.
\end{abstract}

Keywords: Photonics education, optics, laser, technology, Michigan, college, photonics technician.

\section{INTRODUCTION}

A bright spotlight has been shining over the field of photonics in the past couple of years through the efforts of organizations such as the National Photonics Initiative ${ }^{1}$ (NPI) that seeks to raise awareness about the importance of the field and obtain more funding and investment for it in the United States. NPI has identified five key photonics-driven fields: advanced manufacturing, communications and information technology, defense and national security, energy, and health and medicine. With expected continued growth in these fields, increasing numbers of skilled workers will be needed, including at technician level. OP-TEC ${ }^{2}$, the NSF supported National Center for Optics and Photonics Education, has conducted several surveys of the photonics industry in the United States focused on the current and projected need for photonics technicians. The most recent survey ${ }^{3}$, conducted in 2012, found a projected need for more than 4,000 photonics technicians in the next five years. At the same time, the few two-year photonics education programs at colleges in the United States are producing a total of about 250 graduates each year, which is not enough to satisfy the industry needs.

A similar picture describes the situation in the Midwest and specifically in Michigan. The state has a long and rich tradition in optics and photonics research conducted at world class universities. On the commercial side there are more than 50 photonics companies in the state, spanning a wide range of focus, from materials to components for lasers, devices and instrumentation, to end user. The Mi-Light Michigan Photonics Cluster ${ }^{4}$ was formed at the end of 2012 to serve as the focal point for the photonics industry in Michigan. The number of Cluster members grew from 12 founders to more than 30 members currently. The Cluster was successful in obtaining a grant from the Michigan Economic Development Corporation to support the growth of the photonics industry in the state. One of the core areas of focus of the Cluster is supporting education and workforce development in photonics.

Recognizing the documented need for well-trained photonics technicians in Michigan and across the United States, Baker College started the formal process of introducing a new Associate level program focusing on photonics in 2012. Throughout this endeavor the College received support in various forms from OP-TEC and Mi-Light. In addition, Baker College submitted a grant application to the National Science Foundation (NSF) Advanced Technological Education Program in fall 2012, which was approved. The NSF grant supports the development and introduction of the new program. The grant period is July 1, 2013 - Dec. 31, 2015. The new Associate of Applied Science in Photonics and Laser Technology program, the first of its kind in the state of Michigan, started with a first group of students in fall 2013.

*anca.sala@baker.edu; phone 1810 766-4111; fax 1810 766-4042; www.baker.edu

Optics Education and Outreach III, edited by G. Groot Gregory, Proc. of SPIE Vol. 9188,

918803 @ 2014 SPIE · CCC code: $0277-786 \mathrm{X} / 14 / \$ 18 \cdot$ doi: $10.1117 / 12.2061426$ 


\section{DEVELOPING THE PHOTONICS AND LASER TECHNOLOGY PROGRAM}

The overarching goal of the new program is to produce graduates well prepared to contribute to photonics companies in Michigan and in other states. The program name has been chosen to emphasize the field of photonics and particularly lasers as an area of special interest for the industry in Michigan. The program aims to provide fundamental knowledge in optics and photonics combined with hands-on experimental work in well-equipped laboratories where students experience up-to-date devices and instrumentation. As a Career College, Baker College stresses the importance of the application of knowledge to the area of study chosen to get students ready for employment as soon as they graduate. In addition to having experimental lab components in a majority of the core courses, each Baker College program requires an internship or co-op experience with a company prior to graduation.

An Advisory Board bringing together industry representatives and college faculty and administration was formed and started meeting the year prior to the new program introduction. Five commercial companies and Mi-Light Michigan Photonics Cluster have representatives on the Board. The Advisory Board is a key constituent of the Photonics program, providing recommendations on curriculum and laboratory equipment, keeping college faculty up-to-date with advances in the field and sharing a variety of information such as internships and jobs. The Board meets two times per year.

The development and implementation of the new program has proceeded in parallel with the completion of the objectives of the NSF grant project. These objectives are: a) create and implement a new Associate of Applied Science Photonics and Laser Technology (AAS PLT) program; b) fully equip an Optics and Photonics Laboratory for education and training; c) train faculty to teach core courses in the AAS PLT program; d) perform outreach activities to local high schools to promote the new program; e) educate 30 or more students or workers by the end of the project.

\subsection{Program Curriculum}

The program curriculum includes foundation courses in mathematics, physics and basic electric circuits followed by optics and photonics courses. The aim of the optics and photonics core curriculum is to provide students with a solid optics base on which to build towards lasers and modern photonics applications. The curriculum was finalized based on input from several groups: OP-TEC, The Lasers and Electro-Optics program at Indian Hills Community College in Iowa, and the program Advisory Board.

The breakdown of courses by area is shown in Table 1 below. Please note that Baker College operates on a quarter basis with fall, winter, and spring quarters, each 10 week long. The equivalent number of credits on a semester basis is shown in the last column to the right.

Table 1. Photonics and Laser Technology program credits vs area.

\begin{tabular}{|l|c|c|}
\hline \multicolumn{1}{|c|}{ Category } & Quarter Credits & Semester Credits \\
\hline General Education & 25 & 17 \\
\hline Mathematics and Physics & 16 & 11 \\
\hline Basic Electric Circuits & 20 & 3 \\
\hline Computer Aided Design & 4 & 24 \\
\hline Optics and Photonics & 36 & 3 \\
\hline Internship/Co-op & 4 & $\mathbf{7 0}$ \\
\hline Total credits & $\mathbf{1 0 5}$ & \\
\hline
\end{tabular}

The optics and photonics courses that make up the core of the program, in approximately the sequence they are taught, are listed on the next page. With the exception of Photonics Applications all the other courses include both lecture and lab components. At this time the majority of these courses have been developed and taught. Courses yet to be completed and introduced in the classroom are Laser Systems, Optical Systems Analysis, and Photonics Applications. 
- Introduction to Photonics and Laser Technologies

- Geometrical Optics

- Wave Optics

- Laser Fundamentals

- Laser Systems

- Optical Systems Analysis

- Photonics Applications

- Fiber Optics and Data Communications

- Capstone Project.

The internship/co-op requires a minimum of 120 hours of work in the industry towards the end of the program of study. Students graduating from the program have the option to continue their education with a Bachelor degree in a related engineering technology discipline.

\subsection{Optics and Photonics Laboratory}

A well-equipped laboratory is essential in technology programs focused on applications and aiming to provide students with hands-on skills in the core discipline of their program. The Optics and Photonics Laboratory was built in stages. It started by sharing space with the Electronics Laboratory, and then moved to its own dedicated room. Current lab equipment includes optical tables, optical breadboards, Optics Education Kits (Newport Corp) with He-Ne lasers, photometers, optical power meters, Nd-YAG laser and laser diode (PI miCos), fiber laser (IPG Photonics), high power detector and power meter (Ophir - Spiricon), and miscellaneous other components. Digital oscilloscopes are available to measure time dependent characteristics of lasers. The Lab is not yet complete in terms of the equipment needed to deliver all courses in the program. Equipment to be acquired in the near future includes other types of lasers $\left(\mathrm{CO}_{2}, \mathrm{Ar}-\right.$ ion), beam profilers, and an optical spectrum analyzer. General safety and laser safety in particular are emphasized throughout the entire program.

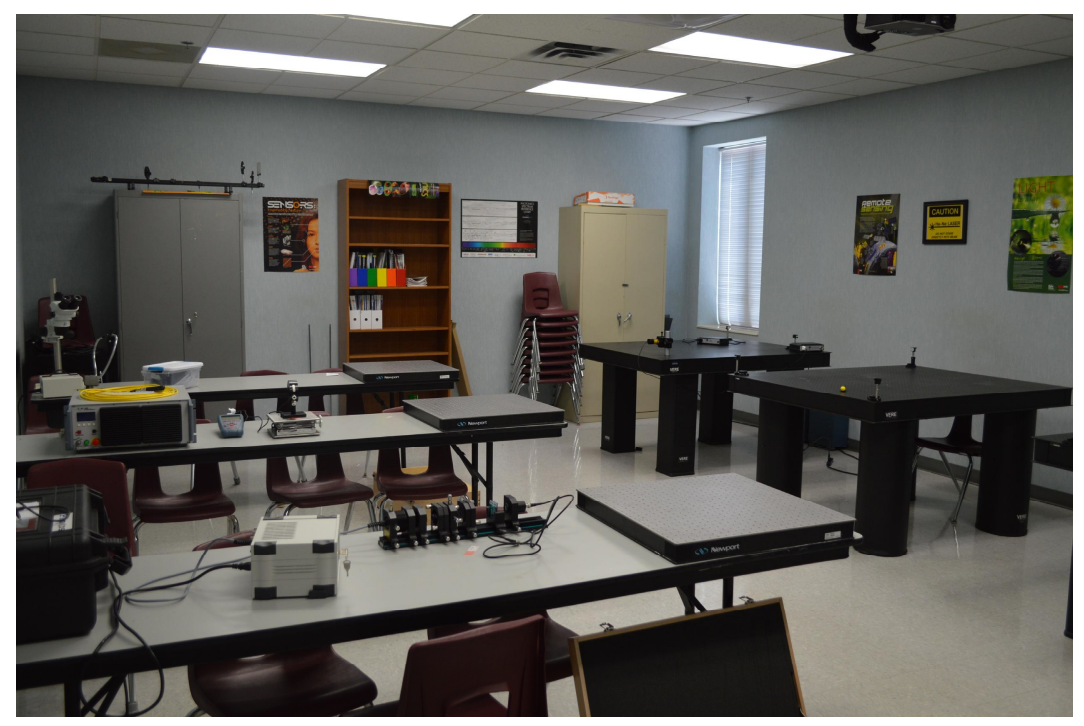

Figure 1. Optics and Photonics Laboratory at Baker College of Flint. 


\subsection{Current State of the Program}

The Photonics and Laser Technology program currently enrolls 12 students in various stages of completion. Baker College as a whole enrolls a large number of non-traditional students and that is also true in the case of the Photonics program. Very few of the students are recent high school graduates. Several students have transfer credits from other colleges, and others are mature adults or veterans who are interested in changing their career. Some students go to school on a part-time basis while others take a full load of courses each quarter. This presents a bit of challenge in terms of being able to place students in the best courses in a given quarter. While general education courses are offered yearround, the technical courses are generally offered only one time per year, following the so-called "rotation schedule". Even with these challenges we were able to provide all students with a good path towards completion of their degree. Program enrollment is expected to grow as we move into the second year and beyond.

Two of the 12 students are close to completing the program, and are expected to graduate in March 2015. These students were recruited from the graduating class of Associate of Applied Science in Electronic Technology. The Electronic Technology program has a large course overlap with the Photonics and Laser Technology program, making it attractive to get a second Associate in one additional year. There are only 7-8 required courses in each program not common between the two. A dual Associate in Electronics \& Photonics as a possible new stand-alone program is under consideration. Students will be able to complete the dual Associate in three years, and will have depth in both areas making them attractive to some employers. The advantage of going this route is in better planning to efficiently complete all program courses, vs. focusing on the two majors in a sequence.

\subsection{Outreach Activities}

As numerous studies ${ }^{5}$ have shown, not enough young people today are interested in and choosing careers in Science, Technology, Engineering and Mathematics (STEM). The field of Photonics has the "cool" factor and the potential to excite the imagination of young people, but they need to be exposed to it throughout their K-12 years. At Baker College we are conducting Photonics outreach year-long. Activities throughout the academic year include visits to and demonstrations in the Optics and Photonics Laboratory during the annual Open House and whenever there is interest from various groups. During the summer we are offering week-long camps for high school students and middle school students, exposing them to a variety of engineering and technology topics.

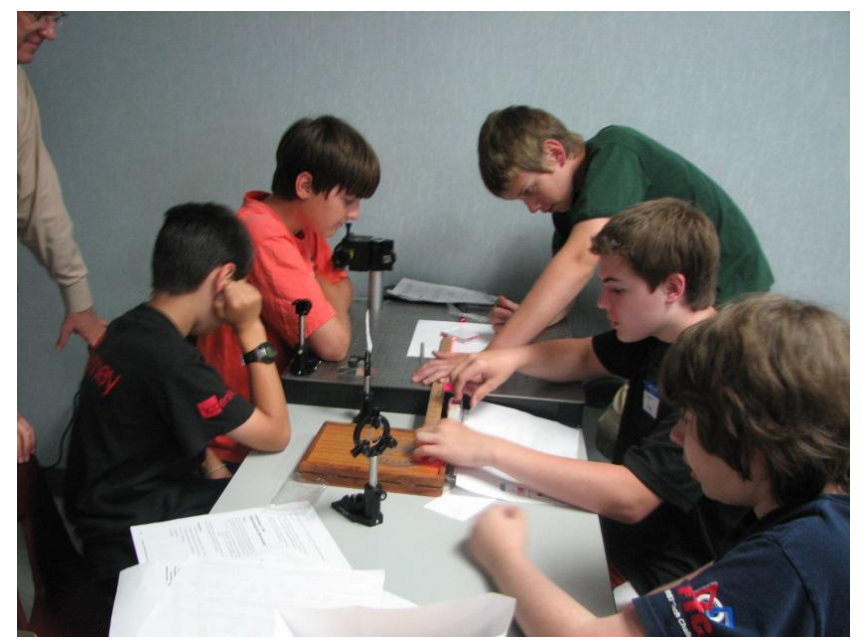

Figure 2. Introduction to Photonics during the 2013 middle school summer camp at Baker College of Flint.

The 2013 middle school camp included one three-hour module to introduce photonics to students. The program was expanded in 2014 when we had two sessions, each three hours long. Students learned about the spectrum of light and observed it for different light sources such as natural light, fluorescent light, incandescent light bulbs, compact fluorescent light bulbs, and LED light bulbs. Experiments illustrating reflection and refraction were performed, followed by experiments with lenses and telescopes, and concluding with a measurement of the speed of light in an acrylic block. 19 students participated in the 2014 camp. They enjoyed the activities and were interested in learning about optics and photonics. 


\section{CONCLUSIONS AND FUTURE STEPS}

Introducing a new Associate in Photonics program at Baker College of Flint has been received very favorably inside the institution and in the local area. At national level, press releases about the new program have been picked up by professional and trade publications such as Laser Focus World, Photonics.com, and Novus Light. The author was invited to two local radio talk shows to discuss the field of photonics, employment opportunities, and the new Baker College program. The Mi-Light Chair was also on the call during these interviews.

The development of the new program is not yet completed. Three more courses need to be created and introduced, and additional lab equipment needs to be acquired. From the starting point, where an initial survey about photonics technicians needs was distributed to 60+ companies in Michigan in fall 2011, until the program will be fully implemented in winter 2015 there was a long way. During this time frame the author also wrote and submitted the NSF grant to support the program. The successful grant application brought with it its own set of requirements which must be satisfied along the way.

The first two graduates of the program are expected in March 2015 followed by another group in December 2015. Once completed the program will be subject to a continuous improvement process, where feedback is gathered from the Advisory Board, employers, students, graduates, and faculty resulting in actions to improve and update the program.

In addition to completing the development of the program, several other activities are planned for the future. Opportunities to offer short-term not-for-credit training courses will be investigated with photonics employers in the state. These courses can be offered in various formats, at employer location or at Baker College, and with flexible schedules. Following a model from OP-TEC, hybrid courses can be offered where the theoretical components are delivered remotely and the lab portions are done on campus.

Another future activity is hosting a Conference about Photonics Education at Baker College, envisioned for fall 2015. The Conference will bring together colleges and employers throughout the state and possibly neighboring states to discuss photonics opportunities and available resources.

The overall experience of introducing the two-year program in photonics at Baker College has been very positive and rewarding. The timing of the new program has been just right, with many synergistic efforts to promote photonics and encourage more participation in the field taking place in Michigan and across the US. The author hopes this experience can motivate other colleges to introduce photonics programs and is open to share information with interested colleagues.

\section{ACKNOWLEDGMENTS}

This paper is based upon work supported, in part, by the National Science Foundation Advanced Technological Education program, under Grant DUE \# 1304071. Any opinions, findings, and conclusions or recommendations expressed in this material are those of the author and do not necessarily reflect the views of the National Science Foundation.

\section{REFERENCES}

[1] National Photonics Initiative, www.lightourfuture.org

[2] OP-TEC, The National Center for Optics and Photonics Education, www.op-tec.org

[3] "Industry Demand for Two-Year College Graduates In Optics and Photonics Technology", OP-TEC, 2012, http://www.op-tec.org/2012survey.php

[4] Mi-Light, The Michigan Photonics Cluster, www.mi-light.org

[5] Gates, S.J., Mirkin, C., "Encouraging STEM Students Is in the National Interest", the Chronicle of Higher Education, June 25, 2012, http://chronicle.com/article/Encouraging-STEM-Students-Is/132425/ 